\title{
Acute myocardial infarction after a wasp sting
}

\author{
ELIZABETH JONES, * M JOY \\ From St Peter's Hospital, Chertsey, Surrey
}

SUMMARY A 56 year old man with ischaemic heart disease and known allergy to wasp venom was stung in the mouth by a wasp and within four hours sustained an acute myocardial infarction. This $\vec{\omega}$ complication has been described on only three previous occasions. Possible pathogenic mechanisms include the anaphylactic reaction itself, the action of wasp venom constituents, and therapeutic intervention with adrenaline.

Anaphylaxis after an insect sting usually presents as hypotension, bronchospasm, and laryngeal oedema. Electrocardiographic changes, ${ }^{1-3}$ chest pain, ${ }^{4}$ and three instances of acute myocardial infarction ${ }^{5}$ - two in North America and one in Sweden-have been described. We report a case of myocardial infarction complicating a wasp sting in the United Kingdom.

\section{Case report}

A 56 year old man was stung in the mouth by a wasp in a glass of lager. Within two minutes he became acutely breathless and experienced tight central chest discomfort. He had a history of urticaria after a previous wasp sting. Three years before he had had an uncomplicated inferior myocardial infarction but a subsequent exercise electrocardiogram had suggested multivessel disease. Two years later he had undergone three vessel coronary artery bypass grafting although he was symptom free at this time. He had remained symptom free after operation and had a good exercise tolerance.

When he arrived at an accident and emergency department 40 minutes after being stung he was restless and hypotensive (systolic blood pressure 65 $\mathrm{mm} \mathrm{Hg}$ ). Periorbital oedema was evident. An electrocardiogram (figure a) showed abnormal $Q$ waves in leads II, III, and aVF, which had been recorded on earlier electrocardiograms and were consistent with the previous inferior myocardial infarction. There was early acute ST-segment elevation both in these leads and in the chest leads V2-V5. Treatment for anaphylactic shock was started with hydrocortisone,

Requests for reprints to Dr M Joy, St Peter's District General Hospital, Guildford Road, Chertsey, Surrey KT16 0PZ.

^Present address: St George's Hospital, Blackshaw Road, London SW17.

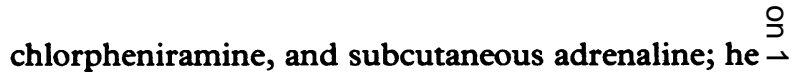
improved. The electrocardiographic changes were $\frac{}{0}$ not recognised and he was discharged home. $\mathrm{He}=$ experienced no further chest pain but was referred $\overrightarrow{0}$ for further assessment 10 days later with fatigue, $\infty_{\infty}^{\infty}$ breathlessness, and weight gain. On examination the blood pressure was $95 / 60 \mathrm{~mm} \mathrm{Hg}$ with a heart rate of 82 beats $/ \mathrm{min}$. The venous pressure was raised with an $8 \mathrm{~cm} \mathrm{~V}$ wave and a distinct third heart sound was heard. An accelerated iodiojunctional rhythm with $\frac{\circ}{\varnothing}$ right bundle branch block and changes typical of $a \stackrel{\varrho}{\Rightarrow}$ substantial transmural anterior myocardial infarc- $\frac{0}{3}$ tion were recorded. He subsequently reverted to sinus rhythm but abnormal $Q$ waves persisted in leads V2-V5 (figure b) and the T waves in II and aVF (that had previously been upright) remained $\mathbb{D}$ inverted. A multiple gated acquisition study showed a dilated left ventricle, an immobile interventricular $\frac{5}{3}$ septum, and a left ventricular ejection fraction of 0.22. (normal $\geqslant 0 \cdot 60$ ). Cardiac catheterisation showed poor left ventricular function and thrombosis of all three grafts with occlusion of the left anterior descen-음 ding artery. Before operation this vessel had been $?$ severely narrowed proximally. Anterior and inferior myocardial infarction was confirmed by exercise ${ }_{\sigma}^{N}$ thallium myocardial scintigraphy.

\section{Discussion}

The patient's symptoms immediately after the wasp sting are attributable either to anaphylaxis or to acute@ myocardial ischaemia or to both. Subsequent events, however, confirmed that he had an acute anterior myocardial infarction, with possible extension of a $\overrightarrow{\widetilde{\rho}}$ previous inferior infarction, at or around the time of the wasp sting, and it is tempting to suggest a cause $\frac{\varrho}{\sigma}$ and effect relation. Subsequent coronary angiography suggested that the infarction was caused byo 


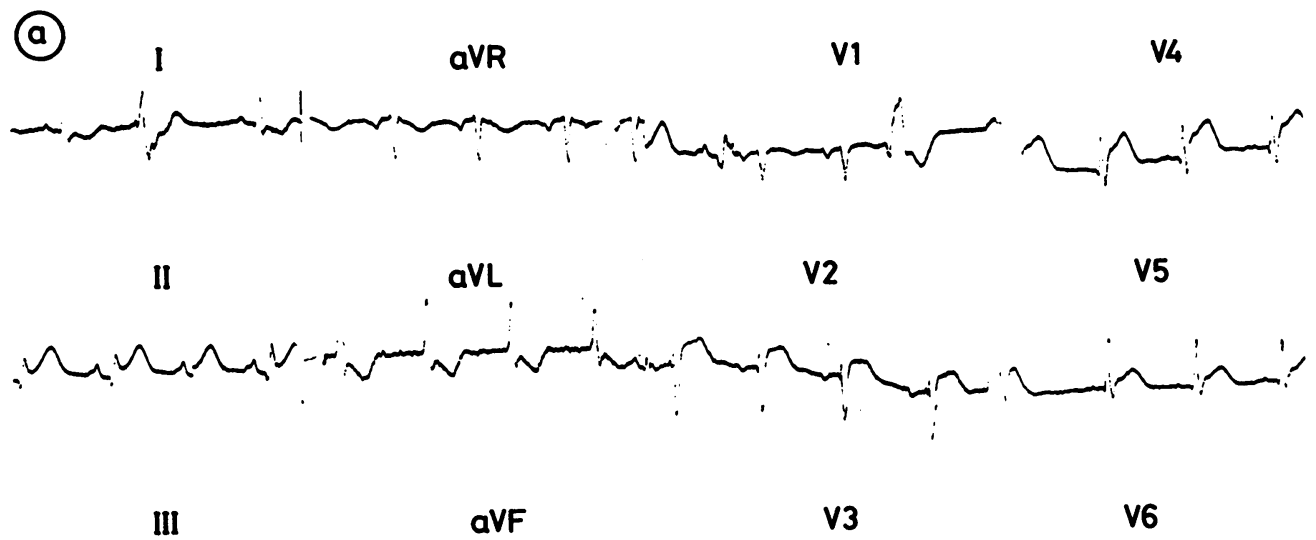

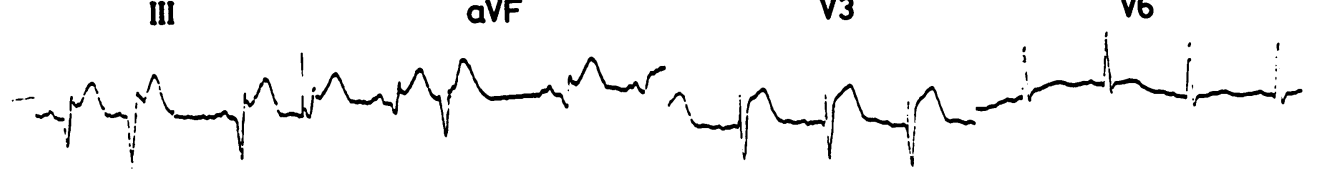

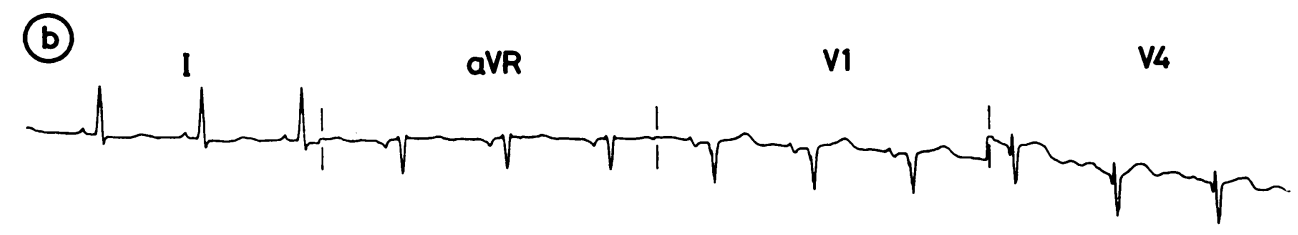

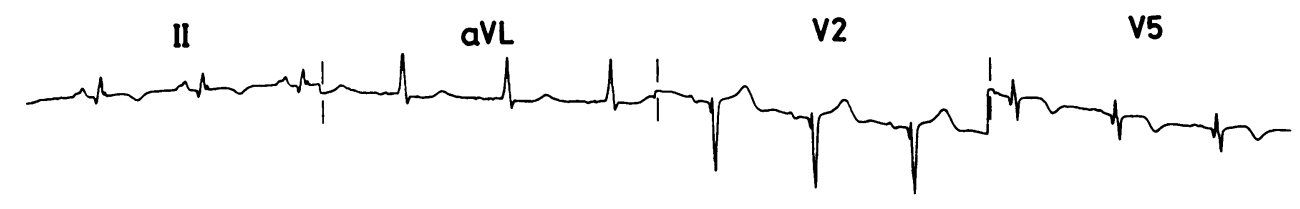

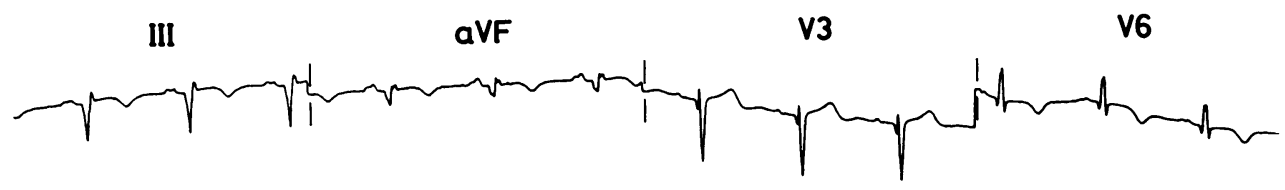

Figure. Electrocardiogram of patient four hours after wasp sting, showing wicuspread inferior and anteroseptal ST-segment elevation (a). Resolution had occurred 11 days later (b) but the appearance of abnormal $Q / Q S$ waves suggested that a transmural anterior myocardial infarction had occurred.

occlusion of the left anterior descending artery or the graft to this vessel or possibly both. Without a postoperative angiogram it is impossible to know when graft occlusion occurred. If one or more grafts were already partially occluded, the haemodynamic events at the time of the wasp sting might have sufficiently reduced coronary blood flow to facilitate thrombosis, but other pathogenetic mechanisms are likely to have been operating.
The reaction to a wasp sting can be prolonged or severe in allergic individuals and in some cases anaphylaxis may ensue, with urticaria, circulatory collapse, and bronchospasm. This is the result of a sequence of events including the release of serotonin and histamine and the formation of leukotrienes, ${ }^{6}$ some of which are potent coronary vasoconstrictors in various animal species. ${ }^{78}$ Many pharmacologically active constituents of wasp venom have been isolated 
including histamine, serotonin, dopamine, noradrenaline, and a bradykinin-like substance which may itself induce histamine release. ${ }^{9}$ Endogenous secretion of adrenaline and noradrenaline is stimulated by histamine and serotonin. All these substances can provoke myocardial ischaemia either via profound hypotension or by increasing myocardial oxygen demand through direct inotropic or chronotropic effects in the presence of a compromised myocardial blood supply.

Platelet aggregation is induced by serotonin ${ }^{10}$ and adrenaline. ${ }^{112}$ Adrenaline also accelerates thrombus formation in animals and in man, possibly by increased factor $\mathrm{V}$ activity, ${ }^{13}{ }^{14}$ and has been shown in animals to release a thromboplastin-like substance from the walls of blood vessels. ${ }^{15}$ It causes both coronary vasodilatation and increased myocardial oxygen demand by direct inotropic and chronotropic effect. It has been used historically as a provocation test for angina pectoris and is often used in the treatment of anaphylactic shock. In two previously reported cases of acute myocardial infarction after wasp stings, chest pain occurred after the administration of adrenaline and diagnostic electrocardiograms were subsequently obtained. ${ }^{5}$ In our patient chest pain occurred within minutes of the sting but before adrenaline was given. But the possibility remains that the myocardial infarction was precipitated by exogenous adrenaline, and it is conceivable that the sting and the infarction were not related.

Acute myocardial infarction after an insect sting is rare, only three unequivocal cases have been reported world wide. ${ }^{5}$ Since numerous electrocardiographic changes have been reported in association with anaphylaxis and after insect stings in subjects without evidence of coronary artery disease,,$^{1-3}$ the electrocardiogram at presentation is unlikely to be helpful in predicting which patients are at risk of myocardial ischaemia. It would thus seem reasonable to use adrenaline with caution in those with a history that is suggestive of coronary insufficiency, although adrenaline should not be withheld in this life threatening situation.
We thank Dr Michael Webb-Peploe of St Thomas's Hospital for performing the angiography.

\section{References}

1 Maretic Z. Electrocardiographic changes following bites and stings of venomous animals. Arh Hig Rada $\mathrm{c}$ Toksikol 1982;33:325-34.

2 Castberg T, Schwartz M. Changes in the electrocardiogram during allergic shock. Acta Med Scand $\vec{\omega}$ 1947;126:459-71.

3 Brasher GW, Sanchez SA. Reversible electrocardiographic changes associated with wasp sting anaphylaxis. if JAMA 1974;229:1210-1.

4 Milne MD. Unusual case of coronary thrombosis 0 [Letter]. Br Med J 1949;i:1123.

5 Levine HD. Acute myocardial infarction following 옥 wasp sting. Am Heart J 1976;91:365-74.

6 Bach MK. Mediators of anaphylaxis and inflammation. Annu Rev Microbiol 1982;36:371-413.

7 Michelassi F, Landa L, Hill RD, et al. Leukotriene D4: a potent coronary artery vasoconstrictor associated $\varnothing_{\infty}$ with impaired ventricular contraction. Science ${ }^{\circ}$ 1982;217:841-3.

8 Piper PJ. Pharmacology of leukotrienes. Br Med Bull 1983;39:255-9.

9 Habermann E. Bee and wasp venoms. Science 1972;177:314-22.

10 Baumgartner HR, Born GVR. Effects of 5-hydroxytryptamine on platelet aggregation. Nature 1968; 218:137-41.

11 McMillan R, Bakich MJ, Yelenosky RJ. The adrenaline binding site on human platelets. Br J Haematol 1979;41:597-604.

12 O'Brien JR. Some effects of adrenaline and anti-adrenaline compounds on platelets in vitro and in vivo.? Nature 1963;200:763-64.

13 Cannon WB, Gray H. Factors affecting the coagulation time of blood. Am J Physiol 1914;34:232-42.

14 Forwell GD, Ingram GIC. The effect of adrenaline infusion on human blood coagulation. $J$ Physiol 马 (Lond) 1957;135:371-83.

15 Shimamoto T, Ishioka T. Release of a thromboplastic substance from arterial walls by epinephrine. Circ Res 1963;12:138-44. 